\title{
CORRECTIONS
}

\section{Climate change and human survival}

The editorial by McCoy and colleagues (BMJ 2014;348:g2351, doi:10.1136/bmj.g2351) stated that "The release of just another 275 gigatonnes of carbon dioxide would probably commit us to a temperature rise of at least $2^{\circ} \mathrm{C}$-an amount that could be emitted in less than eight years." Instead the text should have read, "The release of just another 275 gigatonnes of carbon would probably commit us to a temperature rise of at least $2^{\circ} \mathrm{C}$ - an amount that could be emitted in less than 25 years."

Cite this as: BMJ 2014;348:g2510

(๑) BMJ Publishing Group Ltd 2014 